\title{
CAPACIDADE CONTRIBUTIVA SUBJETIVA E TRIBUTAÇÃO INDIRETA: CONCILIAÇÃO NECESSÁRIA À JUSTIÇA FISCAL
}

\section{Laura Stefenon Fachini ${ }^{1}$}

Resumo: O princípio da capacidade contributiva, expressamente inserido na Constituição de 1988, é de observância obrigatória. Projeta-se sobre o sistema tributário como um todo, impedindo a regressividade e conferindo proteção ao mínimo vital. Nos tributos indiretos, incidentes sobre o consumo, o princípio é atualmente aplicado apenas em seu aspecto objetivo, pela seletividade, sem considerar as particularidades de cada consumidor. Por meio de pesquisa bibliográfica e de dados estatísticos, objetiva-se demonstrar a insuficiência da seletividade e a necessidade e possibilidade de aplicação da capacidade contributiva subjetiva aos tributos indiretos para concretização plena do princípio e para realização da justiça fiscal.

Palavras-chave: Capacidade contributiva. Tributação indireta. Mínimo vital. Não regressividade. Possibilidades tecnológicas.

\section{SUBJECTIVE ABILITY TO PAY AND INDIRECT TAXATION: NECESSARY CONCILIATION FOR FISCAL JUSTICE}

\begin{abstract}
The ability to pay principle, expressly inserted in the 1988 Constitution, is mandatory. It projects itself on the tax system as a whole, preventing it from being regressive and giving protection to the vital minimum. On indirect taxes, incident on consumption, the principle is currently applied in its objective aspect, through selectivity, without considering the particularities of each consumer. Through bibliographical research and statistical data, it is intended to demonstrate the insufficiency of selectivity and the necessity and possibility of applying the subjective ability to pay to indirect taxes for full realization of the principle and of fiscal justice.
\end{abstract}

Keywords: Ability to pay. Indirect taxation. Vital minimum. No regressiveness. Technological possibilities.

\section{Introdução}

A capacidade contributiva é o princípio basilar do Direito Tributário, servindo como critério de concretização da igualdade no âmbito das normas criadoras de encargos (ÁVILA, 2012, p. 432). Impõe que cada indivíduo contribua para as despesas públicas proporcionalmente à riqueza que possui, promovendo a justiça fiscal. Em seu aspecto

1 * Mestranda em Direito Tributário pela Universidade Federal do Rio Grande do Sul - UFRGS. Endereço eletrônico: laura_fachini@hotmail.com. Endereço postal: Av. Osvaldo Aranha, 824, apto. 74, Bom Fim, Porto Alegre/RS. CEP 90035-191 
objetivo, o princípio se refere aos signos presuntivos de riqueza. Já em seu aspecto subjetivo, diz respeito às características pessoais de cada contribuinte (BECHO, 2011, p. 409). A capacidade contributiva projeta-se sobre o sistema tributário como um todo, exercendo diferentes funções no intuito de proteger o contribuinte e de proporcionar a isonomia tributária.

Nos tributos indiretos, incidentes sobre o consumo, a doutrina refere que o princípio da capacidade contributiva seria aplicável de forma distinta, por meio da seletividade. Ou seja, pressupõe-se a maior ou menor essencialidade de um produto ou serviço e onera-se, de forma mais gravosa, aqueles tidos por menos essenciais. Pela seletividade, não se consideram as características particulares de cada contribuinte, mas os fatos presuntivos de riqueza. Assim, tal mecanismo constitui a aplicação do aspecto objetivo da capacidade contributiva.

Considerando que a Constituição determina a personalização no âmbito dos impostos e a observância da capacidade contributiva pelo sistema tributário como um todo, questionase se o modo como o princípio é aplicado aos tributos indiretos é suficiente para concretizar as proteções e a isonomia por ele preconizadas. Busca-se analisar o princípio da capacidade contributiva, sobretudo no que tange à salvaguarda conferida ao mínimo vital e ao impedimento de um sistema tributário regressivo. Pretende-se detalhar a forma como o princípio é aplicado aos tributos indiretos e fazer um exame da incidência tributária nos diversos extratos sociais, a fim de demonstrar a insuficiência do modelo atual. Por fim, expõese possibilidades a serem adotadas, advindas da inovação tecnológica, visando à realização da justiça social.

O trabalho se justifica na medida em que, todos os dias, milhares de consumidores adquirem bens e serviços onerados por tributos indiretos, imposição que, por não observar a capacidade contributiva subjetiva, é fonte de injustiça. $O$ enfrentamento da questão, negligenciado pela doutrina pátria (BALEEIRO, 2010, p. 1096), faz-se necessário para evidenciar a necessidade de correção da desigualdade provocada, bem como para demonstrar a viabilidade da aplicação do princípio em seu aspecto subjetivo. O método utilizado para tanto será o dedutivo, partindo-se do princípio abstratamente considerado para, posteriormente, analisar sua aplicação concreta. Propõe-se a análise das fontes de pesquisa bibliográfica, doutrinária e legislativa que versarem sobre o tema. 


\section{Capacidade contributiva como princípio constitucional}

A inserção do princípio da capacidade contributiva nas modernas constituições foi muito criticada por alguns autores, sobretudo pela doutrina financeira (GIARDINA, 1961, p. 3), referindo que o princípio seria uma locução ambígua, que poderia conter as mais diversas interpretações (BECKER, 2013, p. 518). A despeito das críticas, a Constituição de 1946 trouxe o princípio de forma expressa em seu artigo 202. Com a Emenda Constitucional 18/1965, esse dispositivo foi revogado. Contudo, retornou ao texto constitucional com a promulgação da Constituição de 1988, que assim dispõe:

Art. 145. A União, os Estados, o Distrito Federal e os Municípios poderão instituir os seguintes tributos: [...]

$\S 1^{\circ}$ - Sempre que possível, os impostos terão caráter pessoal e serão graduados segundo a capacidade econômica do contribuinte [...]

$\mathrm{O}$ art. $145, \S 1^{\circ}$ não é norma discricionária, mas imperativa, de observância obrigatória (MACHADO, 2017, p. 40). A capacidade contributiva garante que a norma tributária não caia no vazio, evitando que incida onde não haja manifestação de riqueza. Mas, antes de tudo, o princípio preserva os direitos fundamentais do contribuinte, proibindo que os tributos sejam excessivos a ponto de comprometer a existência ou o livre exercício de um direito fundamental (AMARO, 2014, p. 163). O princípio da capacidade contributiva impõe que os poderes do Estado realizem a justiça fiscal por meio da igualdade (COELHO, 2015, p, 75). Constitui critério fundamental para concretizar a isonomia na seara tributária (VELLOSO, 2012, p. 75).

A capacidade contributiva determina que a pessoalidade seja observada, sempre que possível, na graduação dos impostos. Isso porque a Constituição de 1988 deu prioridade ao tratamento particularizado, segundo o qual as particularidades de cada contribuinte devem ser consideradas a fim de que lhe seja atribuído tratamento diferenciado à medida que se diferenciar dos outros contribuintes (ÁVILA, 2015, p. 92). A única exceção à pessoalidade diz respeito à impossibilidade de sua aplicação (BALEEIRO, 2015, p. 496) e não a uma mera dificuldade. Nos casos em que a consideração das características particulares se torna impossível ou extremamente onerosa, admite-se a não aplicação da pessoalidade, visto que "sua consideração causaria - pela falta de previsão, controle, coordenação, modicidade e conhecimento - mais generalização do que individualização" (ÁVILA, 2015, p. 92). 
Do princípio da capacidade contributiva emanam algumas funções, que orientam o sistema tributário como um todo: (i) função de pressuposto; (ii) função de critério e (iii) função de limite. Como função de pressuposto, o princípio da capacidade contributiva impõe o respeito a dois elementos essenciais: um objetivo e um subjetivo. Suscintamente, o primeiro diz respeito à necessidade de que a hipótese de incidência de cada tributo revele um índice de força econômica. O segundo diz respeito à verificação da possibilidade de se atribuir determinado índice ao sujeito passivo da obrigação tributária (FALSITTA, 2005, p. 146).

Como pressuposto objetivo, a capacidade contributiva impede que a tributação recaia sobre fatos que não demonstrem força econômica (VELLOSO, 2016, p. 75). O texto constitucional de 1988 já discrimina a competência tributária de cada ente federativo, bem como determina as hipóteses de incidência, ou seja, as realidades econômicas sobre as quais recairá a tributação (BALEEIRO, 2010, p. 1094). Por isso, a aplicação da capacidade contributiva como pressuposto objetivo encontra-se praticamente exaurida na redação constitucional. Entretanto, é possível retirar outra consequência desse pressuposto: a obrigatoriedade de que o legislador autorize, na tributação sobre renda e patrimônio, a dedução das despesas necessárias à produção da renda e à conservação do patrimônio, bem como dos gastos no exercício do trabalho (VELLOSO, 2016, p. 75), porque referidos dispêndios não demonstram força econômica, mas custos necessários à obtenção da renda e à manutenção do patrimônio.

Como pressuposto subjetivo, a capacidade contributiva impede que se exija tributo de quem não tenha capacidade de contribuir. Confere proteção ao mínimo existencial, exigindo que a tributação somente incida após deduzidos os gastos necessários para que o contribuinte e sua família tenham uma existência digna (COÊLHO, 2015, p. 70). Dessa forma, é preciso analisar não apenas a capacidade objetiva de riqueza, mas também o peso exercido pelo imposto sobre a satisfação das necessidades do indivíduo (GIARDINA, 1961, p. 35).

Pela função de critério, o princípio da capacidade contributiva funciona como medida de graduação dos tributos, impondo que a carga tributária seja dividida igualmente entre os cidadãos, conforme a riqueza de cada um (TIPKE; YAMASHITA, 2002, p. 18). Vincula-se a dois planos, um horizontal e outro vertical. No plano vertical, diz respeito à necessidade de que a tributação seja progressiva ou, pelo menos, proporcional, conforme será 
analisado adiante. No plano horizontal, impõe que contribuintes com semelhante capacidade contributiva suportem a mesma carga tributária (CALIENDO, 2005, p. 177).

Como função de limite, o princípio da capacidade contributiva determina o respeito a limites mínimos e máximos na tributação. As normas impositivas não podem incidir sobre os recursos necessários para garantir ao contribuinte e à sua família uma existência digna. A tributação só é legítima quando preservar o mínimo existencial (limite mínimo) (VELLOSO, 2016, p. 75). Como limite máximo, a capacidade contributiva proíbe que a tributação seja tão pesada a ponto de resultar em expropriação do objeto tributado (FALSITTA, 2005, p. 147). Na Constituição de 1988, esse limite vem especificado na proibição à utilização de tributos com efeito confiscatório (art. 150, IV, da CF).

A partir das funções desempenhadas pelo princípio da capacidade contributiva, destacam-se duas projeções: a proteção ao mínimo vital, salvaguarda também depreendida de outros princípios constitucionais, e a imposição de que o sistema tributário, considerado em sua totalidade, não possua caráter regressivo.

\subsection{Princípio que protege o mínimo vital}

O princípio da capacidade contributiva confere proteção ao mínimo vital, seja pela função de pressuposto, colocando-o como pressuposto absoluto subjetivo da tributação, seja pela função de limite, estabelecendo que o mínimo existencial é o limite mínimo a ser respeitado pelas normas impositivas. A capacidade contributiva, entendida como adequação subjetiva ao desembolso, determina que a tributação atinja apenas a capacidade econômica residual, após excluídos os gastos necessários a uma existência digna. Dessa forma, quem possui recursos em montante apenas suficiente para cobrir as despesas necessárias à própria existência, embora possua capacidade econômica, não tem capacidade para contribuir (FALSITTA, 2005, p. 149).

Conforme observa o doutrinador italiano Moschetti (1973, p. 227), todos os tributos precisam observar pelo menos uma característica de personalização: a não tributação do mínimo vital. É por isso que as normas impositivas não devem incidir sobre as pessoas cujos recursos sejam apenas suficientes para a manutenção da própria existência (CARRAZZA, 2013, p. 117). Essa exigência é aplicável a todo e qualquer tributo (VELLOSO, 2016, p. 73), sem exceções. 
Além da capacidade contributiva, a não tributação do mínimo vital encontra respaldo em outros dispositivos do texto constitucional, como, por exemplo, no princípio da dignidade da pessoa humana, fundamento da República, e na erradicação da pobreza e da marginalização e na redução das desigualdades sociais e regionais, objetivos fundamentais da República (DIFINI, 2013, p. 14911). Se os indivíduos que auferem recursos suficientes apenas para manter a própria subsistência forem tributados, a pobreza tende a agravar-se e a mobilidade social resta comprometida.

O Estado Social preocupa-se em reduzir as desigualdades sociais, garantindo, inclusive, um auxílio econômico a quem não possua recursos suficientes à própria existência (ZILVETI, 1998, p.45). Dessa forma, seria contraditório que o Estado Tributário retirasse do contribuinte o mínimo vital, direito que o Estado Social é obrigado a prestar (TIPKE; YAMASHITA, 2002, p. 31). Também seria incoerente que a tributação incidisse sobre os cidadãos sem considerar a satisfação das necessidades mínimas da família, já que a Constituição exigiu atenção às necessidades vitais básicas do trabalhador e de seu grupo familiar pelo empregador, que deve pagar salário mínimo (MOSCHETTI, 1973, p. 229).

A capacidade contributiva exige que o mínimo vital não seja tributado, mas não indica qual deve ser esse valor destinado a suprir as necessidades básicas à existência. Herrera Molina (1998, p. 123) elenca alguns fatores que devem ser considerados na determinação desse valor: (i) o custo de vida, que varia conforme a localização e o tempo, (ii) o grau de bem-estar geral alcançado pela sociedade e (iii) os benefícios sociais fornecidos pelo Estado e/ou demais instituições beneficentes. Aponta como possíveis referências o valor das prestações não contributivas da Seguridade Social, ou o valor do salário mínimo. Tipke e Yamashita (2002, p. 34) referem que, pelo princípio da unidade, o valor do mínimo vital para o Direito Tributário não deveria ser inferior ao montante considerado mínimo pelo Direito da Seguridade Social.

No Brasil, os diferentes ramos do Direito adotam concepções variadas de mínimo vital: (i) salário mínimo, (ii) valor máximo da faixa de isenção do imposto de renda, (iii) montante total possível de percepção a título de assistência social, (iv) máximo recebido pelo regime geral da previdência social (não submetido à contribuição previdenciária constante do art. 195, II, da CF) (CAUREO, 2015, p. 130-131). Para fins deste trabalho, adota-se como mínimo existencial o valor correspondente ao salário mínimo, que também representa o valor mínimo das prestações não contributivas da Seguridade Social. 


\subsection{Princípio que impede a regressividade do sistema tributário}

A capacidade contributiva também desempenha a função de critério para graduação dos impostos. No que tange ao ponto, a doutrina majoritária refere a necessidade de que o sistema tributário, como um todo, seja progressivo ou, pelo menos, proporcional, no intuito de respeitar o princípio em comento. Para Derzi (2014, p. 62), "a Constituição determina que impostos sejam cobrados progressivamente porque devem ser graduados de acordo com a capacidade econômica de cada um (art. 145)". Carrazza (2013, p. 99-101) também sustenta a necessidade de todos os impostos serem progressivos para atenderem à capacidade contributiva. No mesmo sentido, Becho (2011, p. 412) menciona que a progressividade seria a única forma de atingir a capacidade contributiva e, por consequência, de realizar a justiça. Baleeiro (2010, p. 1165) também defende que a aplicação da personalização aos impostos prevista no art. $145, \S 1^{\circ}$, da CF só é possível por meio da progressividade.

O princípio da capacidade contributiva não impõe que cada imposto seja progressivo em sentido pleno, mas exige que os impostos e que o sistema tributário como um todo sejam informados por critérios de progressividade. Para tanto, é possível que existam diferentes formas de concretizar a personalização no âmbito dos tributos, a fim de graduar a imposição conforme a capacidade contributiva de cada um (MOSCHETTI, 1973, p. 226). Destaca-se que o princípio deve ser analisado levando-se em conta o sistema fiscal em sua globalidade.

Alguns doutrinadores, de forma isolada, defendem que, em razão da dificuldade de se aferir a capacidade contributiva pela progressividade, esta não deveria ser aplicada (ZILVETI, 1998, p. 41). Outros afirmam que não se pode inferir, a partir da capacidade contributiva, a necessidade de que a alíquota seja progressiva, mas que a progressividade é adequada à realização do princípio (TIPKE; YAMASHITA, 2002, p. 35). Contudo, é concorde a doutrina no sentido de que o legislador não pode variar a alíquota ou o ritmo da progressividade em sentido contrário ao incremento de renda ou de patrimônio dos contribuintes (BECKER, 2013, p. 534-535). Ou seja, o princípio da capacidade contributiva exige que o sistema tributário como um todo, se não for progressivo, pelo menos, não seja regressivo. 


\section{Capacidade contributiva e tributação indireta}

De forma geral, diz-se que, nos tributos indiretos, seria muito difícil, senão impossível, observar a pessoalidade e, por consequência, o princípio da capacidade contributiva subjetiva, visto que a sua aplicação exigiria uma análise das particularidades de todos os contribuintes que adquirissem produtos ou serviços submetidos à tributação indireta (BALEEIRO, 2015, p. 496). É preciso identificar quais são os tributos indiretos para, então, verificar se o princípio da capacidade contributiva é a eles aplicado e, em caso positivo, como se dá sua utilização.

\subsection{Classificação polêmica}

A classificação dos tributos em diretos e indiretos é antiga e polêmica. Sucintamente, são considerados diretos os tributos suportados pelo sujeito passivo indicado pela lei. São indiretos aqueles formalmente pagos pelo contribuinte indicado na lei, contudo, efetivamente suportados por outro, o chamado contribuinte de fato (CONTI, 1996, p. 48-49). Assim, podese dizer que o critério que fundamenta a classificação dos tributos em direitos e indiretos é a possibilidade ou não de transferir o encargo fiscal a um terceiro, seja em decorrência de previsão legislativa, de contrato firmado, ou de mecanismos de preço (COÊLHO, 2015, p. $71)$.

O critério adotado para classificar os tributos em direitos e indiretos é criticado por muitos. Para Becker (2013, p. 573-575), a repercussão econômica é critério artificial e errado, sem qualquer fundamento científico. Amaro $(2014$, p. 112) também alerta para que se tenha cuidado com esta classificação, porquanto, sob a ótica jurídica, todos os contribuintes são "de direito", porque indicados na lei. Além disso, pode ser que os tributos tidos por indiretos não sejam repassados em sua integralidade ao terceiro, contribuinte de fato. Da mesma forma, é possível que os tributos diretos, por algum artifício, sejam justapostos aos preços de produtos e serviços, sendo, por fim, suportados por um terceiro diferente do contribuinte indicado pela lei.

Carvalho (2017, p. 320) reforça o enfoque econômico e pré-legislativo da classificação dos tributos em direitos e indiretos e a situa no campo de estudos da Economia ou da Ciência das Finanças. Isso porque a relação econômica do sujeito indicado pelo 
legislador com a situação geradora do liame fiscal não é problema jurídico. Ao Direito, interessa a norma que ingressou no sistema e quem foi por ela indicado como integrante do vínculo obrigacional.

Para contornar as críticas mencionadas, a doutrina passou a distinguir entre a repercussão financeira (econômica) e a jurídica, a fim de determinar quais tributos comportam transferência do respectivo encargo financeiro. Nesse sentido, a repercussão econômica é préjurídica ao passo que a repercussão jurídica é aquela válida perante o Direito. Como fator comum, em ambas as repercussões, há uma realidade econômica subjacente: a diminuição de patrimônio em razão do pagamento do tributo. Como fator diferenciador, a repercussão jurídica é recepcionada pelo ordenamento, tendo valor no plano jurídico, o que não ocorre com aquela meramente econômica (AMARAL, 1991, p. 355-356). Assim, a repercussão jurídica configura-se pela existência de uma norma jurídica que permita, de forma expressa, a transferência do ônus tributário a um terceiro (TIPKE; YAMASHITA, 2002, p. 105). Essa diferenciação proposta pela doutrina encontra fundamento no art. 166 do Código Tributário Nacional.

A despeito das críticas à classificação dos tributos em direitos e indiretos e das distinções entre repercussão jurídica e econômica, fato é que, na prática, o termo "tributos indiretos" é largamente aplicado (CAUREO, 2015, p. 112), não apenas para designar aqueles impostos em que há repercussão jurídica, mas, sobretudo, para fazer referência os tributos incidentes sobre o consumo (COÊLHO, 2015, p. 416). Nesse sentido, são indiretos os tributos que visam gravar a capacidade econômica do consumidor final, não a da empresa, finalidade que pode ser depreendida de uma análise da lei, de suas técnicas de imposição, de seu texto, de suas intenções (LAPATZA, 2003, p. 165). O ICMS tributa o consumo final, da mesma forma que o IPI, haja vista não onerarem a força econômica da empresa, porque independem do resultado desta (BALEEIRO, 2015, p. 475). Também o ISS é considerado indireto nessa concepção. Em relação ao PIS e à COFINS, não há consenso (CAUREO, 2015, p. 112). Para fins deste trabalho, cujo objetivo é demonstrar o ônus tributário efetivamente suportado pelos extratos sociais, adotar-se-á a concepção de tributos indiretos como aqueles incidentes sobre o consumo e assim considerados pelos economistas quando realizam estudos sobre o tema.

\subsection{Aplicação da capacidade contributiva objetiva aos tributos indiretos}


A doutrina costuma referir que os tributos indiretos obedecem à capacidade contributiva, contudo, o critério utilizado para aplicação do princípio é distinto (CONTI, 1996, p.67-68). Nos tributos indiretos, não há mensuração exata da capacidade contributiva do consumidor final, que efetivamente arca com o ônus fiscal. O que há é uma presunção de poder de compra conforme o bem adquirido (KIRCHHOF, 2016, p. 35). A vertente de aplicação do princípio da capacidade contributiva aos tributos indiretos revela-se por meio da seletividade, determinando que o gravame seja menor à medida que o bem for mais essencial (AMARO, 2014, p. 165). Dessa forma, os produtos de primeira necessidade, como os que compõe a cesta básica do trabalhador, não devem sofrer incidência de IPI e de ICMS, ou, pelo menos, devem ser menos onerados do que os produtos voluptuários (CARRAZZA, 2013, p. 110).

A seletividade foi escolhida como meio de tornar simples e viável a aplicação da lei. Tipke e Yamashita (2002, p. 38-39) referem que, caso houve leis detalhadas e diferenciadoras, visando adequar o princípio da capacidade contributiva aos tributos indiretos conforme as particularidades de cada contribuinte, seria impossível aplicá-las de forma isonômica, em tempo razoável e com pessoal disponível, porque os contribuintes são em número de milhões. Neste caso, embora o princípio da capacidade contributiva postule o tratamento particularizado, permite-se estabelecer certa generalização, visto que a consideração das características de cada contribuinte tornaria a fiscalização extremamente onerosa, além de não promover a individualização, pela falta de controle e coordenação (ÁVILA, 2015, p. 89). Entretanto, a tipificação de situações gerais desconsiderando as particularidades do contribuinte deve observar uma normalidade média, ou seja, deve impor um ônus tributário que seja adequado à média dos contribuintes, protegendo o mínimo vital. As normas de simplificação não podem, em nome da praticabilidade, acarretar perda expressiva na concretização da justiça fiscal (TIPKE; YAMASHITA, 2002, p. 38-39).

No cenário atual, o que se tem é a aplicação da capacidade contributiva em sua forma objetiva aos tributos indiretos, por meio da seletividade. Não se leva em consideração as características particulares de cada contribuinte, mas sim, fatos presuntivos de riqueza. A essencialidade do bem, definida previamente a partir de valorações realizadas pelo legislador, é o que determina a existência ou não de isenções ou reduções de alíquotas. 


\section{Insuficiência da capacidade contributiva objetiva: dados estatísticos}

A seletividade, forma de aplicação do princípio da capacidade contributiva em seu viés objetivo, por ser uma forma de simplificação legal, também leva a distorções. Contribuintes economicamente favorecidos, que teriam condições de arcar com ônus tributário mais elevado, também adquirem produtos básicos. Da mesma forma, quando os contribuintes mais pobres adquirir itens tidos por supérfluos, como os relacionados à tecnologia da informação, o valor da tributação por eles suportado é proporcionalmente maior, por conta da parca receita auferida (DANILEVICZ, 2009, p.239). Além disso, quando os produtos de primeira necessidade não são isentos, mas possuem apenas alíquota reduzida, prejudicam-se aqueles que têm maiores responsabilidades familiares, ou seja, maior número de pessoas que dependem de seus rendimentos para sobreviver (HERRERA MOLINA, 1998, p. 457-458). A seletividade como único mecanismo de realização da capacidade contributiva na tributação indireta, ao definir o padrão de consumo a ser adotado pelo contribuinte de parcos recursos, acaba por cercear a liberdade e por dificultar a mudança social (CAUREO, 2015, p. 137-138).

Mas não é só. Essa forma de realização da capacidade contributiva também não se revela suficiente para garantir o mínimo existencial das famílias menos beneficiadas economicamente, muito menos um sistema tributário que, como um todo, não seja regressivo. Tais conclusões são obtidas a partir dos dados estatísticos sobre carga tributária no Brasil. Em 2015, por exemplo, quase metade do total arrecadado adveio da tributação sobre o consumo de bens e de serviços (SANTANA, 2016, p. 8). Para se ter uma ideia, em termos comparativos, o Brasil possui uma carga tributária muito maior sobre bens e serviços do que a média dos países da OCDE. Já em relação à tributação sobre a renda, verifica-se o inverso.

Um estudo realizado pelo IPEA em 2000 (VIANNA et. al., 2000), que tomou por base os dados obtidos na Pesquisa de Orçamentos Familiares (POF) realizada em1995-1996 pelo IBGE, revela que, em relação à distribuição da carga tributária entre os diferentes extratos sociais, os tributos diretos são progressivos. As famílias que recebiam até dois salários mínimos nas regiões metropolitanas dispendiam pouco menos de $2 \%$ de sua renda bruta com este tipo de tributo. Já as famílias com ganhos maiores do que trinta salários mínimos tinham cerca de $11 \%$ de sua renda comprometida com tributos diretos. Já os tributos indiretos são altamente regressivos. As famílias mais ricas (que recebem mais de trinta 
salários mínimos) gastavam apenas $7 \%$ de sua renda mensal com tributos indiretos. Já as famílias que recebiam até dois salários mínimos tinham cerca de $27 \%$ de sua renda comprometida com esses tributos. Observa-se um aumento do comprometimento da renda com tributos indiretos à medida que decrescem os rendimentos auferidos.

Considerando-se a carga tributária total, verifica-se que as famílias mais pobres tinham mais de $28 \%$ de sua renda afetada pela imposição fiscal. Já as famílias mais ricas destinavam apenas cerca de $18 \%$ de sua renda para manutenção dos custos públicos. Pode-se concluir que a carga tributária em relação aos extratos sociais é altamente regressiva. Embora os tributos diretos sejam progressivos, a regressividade dos tributos indiretos é tamanha que desequilibra a distribuição da tributação na sociedade, fazendo com que as famílias mais pobres tenham um percentual muito maior de sua renda comprometido com gastos fiscais ${ }^{2}$.

A regressividade da tributação, ao serem considerados tanto tributos diretos quanto indiretos, também é evidenciada na Tese de Doutorado de Fernando Silveira (2008, p. 103): “o resultado final é a regressividade da carga tributária total, dado que nos $10 \%$ mais pobres ela atinge ao redor de $32 \%$, caindo continuamente até representar, nos $10 \%$ mais ricos, $22 \%$.

Outro estudo realizado em 2007 (ZOCKUN, 2007), vinculado à Fundação Instituto de Pesquisas Econômicas, tomando por base a Pesquisa de Orçamentos Familiares (POF) realizada em 2002-2003, apontou que, entre 1996 e 2004, além de ter havido um aumento na carga tributário global para todos os extratos sociais, avultou a regressividade do sistema. Em relação à tributação direta, as famílias que recebiam até dois salários mínimos em 2003 pagavam cerca de $3 \%$ de sua renda para satisfazer esses tributos. Já as famílias do último extrato, que recebiam mais de trinta salários mínimos, dispendiam 10\%. Observa-se a existência de progressividade na tributação direta. Já os tributos indiretos comprometiam quase $46 \%$ da renda das famílias mais pobres, percentual que se reduzia para $16 \%$ quando analisado o extrato economicamente mais favorecido. Visualiza-se uma regressividade aguda na tributação indireta, que também é constatada na carga tributária global incidente sobre cada extrato social: enquanto as famílias mais ricas tinham $26 \%$ de seus rendimentos onerados com tributos diretos e indiretos, as famílias que recebiam até dois salários mínimos possuíam 49\% de sua renda consumida com encargos fiscais. Considerando que o valor correspondente ao mínimo existencial adotado neste trabalho é o salário mínimo, pode-se afirmar convictamente

\footnotetext{
${ }^{2}$ No estudo realizado, foram considerados IR, INSS, IPTU, IPVA, ICMS, IPI, PIS e COFINS, que representam percentual expressivo (maior que 79\%) da carga fiscal bruta em 1996.
} 
que as famílias cujos rendimentos não ultrapassam dois salários mínimos e cuja carga tributária total incidente chega a $49 \%$ de sua renda não têm garantido o mínimo necessário à sobrevivência.

Em relação à seletividade pela essencialidade do produto, no caso do ICMS, outro estudo realizado demonstra que os maiores benefícios decorrentes das renuncias fiscais são usufruídos pelos extratos mais ricos da sociedade (SILVA, 2018). Os 30\% mais ricos recebem $50 \%$ dos benefícios decorrentes de renúncias fiscais. Já os $30 \%$ mais pobres ficam com menos de $14 \%^{3}$. As renúncias fiscais são contrabalanceadas por mecanismos compensatórios, que consistem, basicamente, em estabelecer alíquota acima da média para produtos e serviços considerados menos essenciais. O estudo demonstrou que os $30 \%$ mais ricos arcam com $57 \%$ deste custo para compensar as renúncias. Já os $30 \%$ mais pobres respondem por 9,5\%. Para verificar o benefício efetivo concedido a cada um dos extratos sociais, é preciso reduzir o proveito recebido a título de renúncia do valor pago a título de compensação. Realizando a operação, verifica-se que o benefício liquido concedido às famílias mais pobres é muito pequeno.

Embora muitos sistemas tributários de países ocidentais possuam uma tendência à personalização e a uma eminente progressividade, o sistema tributário brasileiro continua objetivo e muito regressivo (BALEEIRO, 2010, p. 1160). A desproporção existente entre carga tributária suportada por famílias de baixa renda e encargos fiscais que oneram as famílias de altos rendimentos tem origem na prevalência da tributação sobre o consumo, na qual se desconsideram as particularidades econômicas de cada contribuinte em prol da generalidade da norma. Quanto mais predominar a tributação indireta em um sistema tributário, menor será a garantia de imposição conforme a capacidade contributiva.

Os estudos demonstram que a seletividade não é suficiente para concretizar o princípio da capacidade contributiva, porque não é capaz de assegurar o mínimo vital, nem de garantir que o sistema tributário seja, como um todo, proporcional ou progressivo. O princípio da capacidade contributiva apenas será satisfatoriamente atendido se seus dois aspectos, subjetivo e o objetivo, forem observados na elaboração e na aplicação da lei (BALEEIRO, 2010, p. 1160).

\footnotetext{
${ }^{3}$ O estudo tomou por base o ICMS do Rio Grande do Sul em 2015, "refletindo uma combinação específica de isenções, reduções de base de cálculo e alíquotas, incidentes sobre uma estrutura de consumo e distribuição de renda particular". Entretanto, o autor conclui que os resultados, ao que tudo indica, seriam semelhantes caso o estudo fosse realizado considerando a realidade existente nos demais estados brasileiros.
} 


\section{Possibilidade de aplicação da capacidade contributiva subjetiva aos tributos indiretos}

Atualmente, o que há é a aplicação tão somente do aspecto objetivo da capacidade contributiva aos tributos indiretos, por meio da seletividade. Contudo, para que o princípio da capacidade contributiva seja plenamente realizado, é preciso a consideração também de seu aspecto subjetivo. Com o avanço da tecnologia e dos sistemas de informação, o que era considerado impossível pela doutrina tornou-se factível, existindo algumas possíveis formas para atender também ao aspecto subjetivo do princípio.

Herrera Molina (1998, p. 126) refere que o mínimo existencial e, por consequência, a capacidade contributiva subjetiva, podem ser garantidos na tributação indireta por meio de duas soluções técnicas: (i) exoneração dos bens de primeira necessidade e (ii) pagamento de uma compensação correspondente ao valor dos tributos sobre um consumo mínimo. Isso poderia ser feito mediante crédito no imposto de renda, ou mediante transferência às pessoas de baixa renda. Tipke e Lang (2008, p. 220) também enfocam a necessidade de restituição dos valores onerados por tributos, quando atingirem o mínimo vital. A primeira opção, exoneração dos bens considerados essenciais (seletividade), não é suficiente para garantir a efetiva aplicação do princípio da capacidade contributiva. Assim, a devolução de valores dispendidos em tributos indiretos aos extratos economicamente menos favorecidos é medida que se impõe.

Esta devolução pode acontecer de várias formas. No Brasil, ela ocorre de forma deturpada, por meio dos programas de assistência social. O sistema tributário regressivo existente no país retira, através da tributação indireta, os recursos já escassos da população mais carente. Por meio da assistência social, o que se faz, na verdade, é a restituição dos tributos indevidamente arrecadados, gerando um círculo vicioso reprovável (DERZI, 2014, p. 49). A doutrina denuncia esse modelo de transferência de recursos decorrente de uma constatação não exteriorizada de que o sistema tributário impõe sacrifício desmedido à população carente, sem considerar o princípio da capacidade contributiva (CAUREO, 2015, p. 126). Entretanto, este enfoque é negligenciado, tanto por parte de quem elabora os programas assistenciais quanto por seus beneficiários (DERZI, 2014, p. 49).

A restituição dos valores onerados pela tributação indireta aos extratos sociais mais baixos também pode ser realizada de forma explícita e abrangente, não, como hoje, travestida de programa assistencial. Neste ponto, é possível se valer de experiências existentes no direito 
comparado, nas quais se verifica a devolução de parte ou da totalidade dos tributos incidentes sobre o consumo às famílias com menores condições econômicas.

\subsection{Experiências no direito comparado}

Alguns países já adotam programas de devolução de tributos incidentes sobre o consumo à população mais pobre, visando corrigir as injustiças provocadas por uma tributação objetiva. O Canadá possui um programa de devolução dos impostos sobre vendas a famílias de renda baixa e modesta. É o chamado GST/HST credit $^{4}$, por meio do qual famílias menos favorecidas economicamente compensam, total ou parcialmente, o GST ou o HST (impostos sobre consumo) que pagam. A Receita Federal do Canadá determina a elegibilidade do beneficiário automaticamente, a partir da declaração de imposto de renda (CANADA, 2018).

Os indivíduos qualificados para auferir os créditos recebem do governo canadense um pagamento trimestral isento de impostos. $\mathrm{O}$ valor do crédito é calculado, preponderantemente, de acordo com o rendimento líquido da família/indivíduo e da composição familiar. Por exemplo, um indivíduo solteiro, que receba até $\$ 40.000,00$ por ano terá direito a um crédito de $\$ 281,80 /$ ano. Se tiver um filho, o valor do crédito aumenta para $\$ 565,80 /$ ano. Se o indivíduo for casado, o valor do benefício também progride (CANADA, 2018). Vale lembrar que o imposto federal sobre vendas no Canadá (GST) é de apenas 5\%, e que o HST (imposto federal mais impostos provinciais) varia em torno de 13 e $15 \%$, bem abaixo da média dos países da OCDE (OECD, 2016), e do Brasil. Ademais, algumas províncias cobram apenas o GST.

Nos Estados Unidos, outro exemplo a ser citado é o Programa de Assistência Nutricional Suplementar (SNAP). Consiste no fornecimento, às famílias pobres, de um valor mensal a ser utilizado na compra de alimentos incluídos no programa, como frutas, pães, cereais, vegetais, carne, dentre outros (UNITED STATES, 2018). Até aqui, a descrição leva a crer que se trata apenas de mais um programa de assistência social. Contudo, a novidade é que os produtos elegíveis adquiridos com benefícios advindos do SNAP são isentos de impostos sobre vendas, quando comprados pelos beneficiários do programa (WASHINGTON, 2018).

\footnotetext{
${ }^{4}$ Goods and services tax/Harmonized sales tax (GST/HST) credit. O GST é uma taxa federal com alíquota de $5 \%$ incidente sobre venda de produtos e serviços. O HST é a combinação do GST federal e das taxas sobre vendas de bens e serviços cobradas por cada uma das províncias canadenses.
} 
Para ser elegível ao programa, é preciso que os rendimentos auferidos pelo agregado familiar não excedam os limites estipulados de renda bruta e de renda líquida. $O$ valor do benefício a ser recebido é calculado de acordo com o tamanho da família, a renda familiar mensal e as despesas efetuadas em itens como aluguel, cuidados com crianças e idosos. Por exemplo, um agregado familiar composto por cinco pessoas e que receba $\$ 2.000,00$ mensais terá direito a um benefício mensal de $\$ 160$. Os benefícios concedidos pelo SNAP são emitidos por meio de cartões semelhantes aos cartões de débito. $\mathrm{O}$ benefício é depositado mensalmente na conta do titular. Quando o beneficiário realiza a compra utilizando o cartão, o preço é debitado automaticamente da sua conta, deduzido o imposto sobre vendas (POMERANZ; CHRIQUI, 2015).

A capacidade contributiva objetiva é aplicada pelo mecanismo da seletividade, contudo, por meio do SNAP, não se desconsidera a capacidade contributiva subjetiva, já que as famílias mais pobres são isentas da tributação indireta incidente sobre alimentos. Os estados americanos já aplicam a distinção entre produtos essenciais e não essenciais para fins de tributação, onerando mais os últimos. A despeito disso, os beneficiários do SNAP são isentos tanto das taxas estatais quanto locais, independentemente da alíquota incidente sobre o produto adquirido. Vale lembrar que a proporção de receitas provindas de tributação sobre o consumo em relação à carga tributária total nos Estados Unidos é ínfima, cerca de 7,9\%, bem menor que a média dos países da OCDE e que a média no Brasil (OECD, 2016).

\subsection{Experiências e possibilidades para o Brasil}

No Brasil, já existem alguns programas que permitem a identificação do contribuinte e, consequentemente, possibilitam a aplicação do princípio da capacidade contributiva em seu aspecto subjetivo. A Nota Fiscal Gaúcha é um programa criado em 2012 que visa incentivar os consumidores a incluírem seu CPF no documento fiscal quando realizarem compras (RIO GRANDE DO SUL, 2018). Os benefícios oferecidos pelo programa são, basicamente, participação dos consumidores em sorteio de prêmios e desconto no IPVA. A inspiração foi o Programa de Estímulo à Cidadania Fiscal do Estado de São Paulo, conhecido como Nota Fiscal Paulista, criado em 2007 (PASCHOAL, 2012, p. 56-57). Os benefícios concedidos pelo último programa são mais abrangentes, incluindo desconto no IPVA, crédito em conta corrente ou poupança e sorteio de prêmios. Para participar do programa, é necessário que o 
consumidor faça seu cadastro no sistema e informe seu CPF ou CNPJ no ato da compra, solicitando a emissão do documento fiscal. A Secretaria da Fazenda fará os cálculos para determinar o montante de crédito mensal a ser transferido ao consumidor. Este valor ficará disponível por cinco anos, podendo ser utilizado para abater o débito de IPVA ou transferido para conta corrente ou poupança (SÃO PAULO, 2018).

O benefício é calculado tomando-se por base o valor total de imposto efetivamente recolhido pelo estabelecimento. Deste montante, até 30\% será devolvido aos consumidores que inseriam seu CPF ou CNPJ no documento fiscal, de acordo com o valor da compra de cada um. Pode acontecer que, em determinado período, o estabelecimento não tenha imposto a recolher em razão da existência de crédito. Nos casos em que o produto é sujeito à substituição tributária, ocorre situação semelhante, haja vista que o recolhimento ocorreu de forma antecipa, no início da cadeia. Nestas situações, para que o consumidor não fique sem qualquer benefício, a Secretaria da Fazenda inseriu os sorteios mensais de prêmios em dinheiro no programa.

Em que pese referidos programas não concederem benefícios diretamente associados à capacidade contributiva subjetiva, são bons demonstrativos de que é possível individualizar o contribuinte no momento da compra, por meio da inclusão do CPF desde no documento fiscal, e quantificar o consumo realizado. Esta afirmação é corroborada pela recente proposição realizada por alguns auditores fiscais no sentido de se adotar o Imposto sobre Valor Agregado Personalizado (IVA-P), capaz de promover eficiência e equidade tomando por diretrizes a modernização e a personalização (SILVA, 2018, p. 17-18). O imposto substituiria o IPI, o ICMS e o ISSQN, possuiria alíquota única, poucas isenções e base ampla. Em relação à personalização, as famílias de baixa renda, cadastradas no Cadastro Único para Programas Sociais do Governo Federal (CadÚnico), teriam restituído, parcial ou totalmente, o valor onerado pela tributação. A informação acerca do consumo realizado por cada família seria obtida pela inclusão do CPF na nota fiscal. A compra efetuada pela família seria informada à administração tributária, que calcularia o total das desonerações e, ao final do período, depositaria o valor em conta bancária de titularidade do membro da família.

A proposta mostra um caminho possível para se respeitar o mínimo vital e a não regressividade do sistema tributário como um todo, requisitos necessários para concretizar o princípio da capacidade contributiva. A modernidade cibernética permite o cruzamento de dados, individualizando o perfil de cada contribuinte, bem como as quantidades de bens e 
serviços por ele consumidos (GONÇALVES, 2011). O avanço tecnológico e o direcionamento de softwares para esta finalidade viabilizam que seja montado um cadastro de cada contribuinte, possibilitando o armazenamento e o cruzamento de dados. Na verdade, em relação às famílias que recebem até três salários mínimos mensais, já existe o CadÙnico, que mantém registros atualizados das famílias de baixa renda, contendo informações como características da residência, identificação dos integrantes, de seu trabalho e renda (BRASIL, 2015).

A partir do cadastro de contribuintes e do cruzamento de dados por parte do fisco, será possível aferir a capacidade contributiva subjetiva do adquirente de bens e serviços no ato da compra, bem como quantificar o que foi por ele consumido. Com essas ferramentas tecnológicas à disposição, não será difícil destinar os benefícios fiscais a quem realmente necessite, ou seja, a quem, embora tendo parcos recursos, seja excessivamente onerado pela tributação indireta. Desta forma, o sistema tributário brasileiro estará avançando na realização da justiça fiscal e na concretização do princípio da capacidade contributiva.

\section{Conclusão}

A capacidade contributiva, como princípio constitucional, possui poder normativo, projetando-se sobre o sistema tributário como um todo. Confere proteção ao mínimo vital, proibindo que a tributação incida sobre valores indispensáveis à satisfação das necessidades básicas do contribuinte e de sua família. Como critério de graduação dos impostos, estabelece que a carga tributária incidente sobre cada extrato social seja proporcional ou progressiva em relação ao incremento da receita auferida, impedindo a regressividade do sistema fiscal.

Em relação aos tributos indiretos, incidentes sobre o consumo, a capacidade contributiva é hoje aplicada considerando-se tão somente seu aspecto objetivo, por meio da seletividade, haja vista a suposta impossibilidade de se analisar as particularidades de cada consumidor. No país, a preponderância da incidência tributária sobre o consumo somada à inobservância da capacidade contributiva subjetiva na tributação indireta são responsáveis por violar o mínimo existencial e o mandamento de não regressividade do sistema tributário como um todo. As famílias menos favorecidas economicamente têm seus rendimentos abusivamente onerados para o custeio dos gastos públicos. Um sistema tributário regressivo e transgressor 
do mínimo vital penaliza sobremaneira os mais pobres, provocando desigualdade e injustiça fiscal.

O quadro descrito revela a insuficiência da seletividade como técnica para concretizar a capacidade contributiva, sobretudo em um cenário onde os encargos fiscais sobre o consumo ocupam posição significativa na composição da carga tributária total. Devese considerar também o aspecto subjetivo da capacidade contributiva para que a realização do princípio seja efetiva. Esta consideração, tida por impossível pela doutrina, hoje mostra-se viável por conta das inovações tecnológicas e da evolução dos sistemas informacionais, que permitem identificar o contribuinte no momento da compra, bem como quantificar o consumo realizado.

A restituição de tributos incidentes sobre vendas a famílias de baixa renda já é medida adotada em alguns países como forma de corrigir as desigualdades provocadas por uma tributação objetiva. No Brasil, os programas que incentivam a inclusão do CPF ou CNPJ na nota fiscal mediante concessão de prêmios e outras vantagens revelam a viabilidade de singularizar o adquirente e o que foi consumido. A possibilidade de os softwares cruzarem informações como composição familiar, rendimentos auferidos e gastos realizados permite destinar benefícios fiscais a quem realmente precise. A devolução de valores indevidamente dispendidos com tributos indiretos às famílias menos favorecidas economicamente é medida possível e necessária para concretização efetiva do princípio da capacidade contributiva e para que o sistema tributário brasileiro avance no sentido de se tornar menos regressivo e mais justo.

\section{Referências}

AMARAL, Luiz. Da Repercussão Econômica e da Repercussão Jurídica nos Tributos. Revista de Informação Legislativa. Brasília, a. 28, n. 112, p. 347-356, out./dez. 1991.

AMARO, Luciano. Direito tributário brasileiro. 20 ed. São Paulo: Saraiva, 2014.

ÁVILA, Humberto. Teoria da Igualdade Tributária (2008), 3 ed. São Paulo: Malheiros Editores, 2015.

BALEEIRO, Aliomar. Direito Tributário Brasileiro. Atualização de Misabel Abreu Machado Derzi. 13 ed. Rio de Janeiro: Forense, 2015.

Limitações constitucionais ao poder de tributar. Atualização de Misabel Abreu Machado Derzi. 8 ed. Rio de Janeiro: Forense, 2010. 
BECHO, Renato Lopes. Lições de Direito Tributário: teoria geral e constitucional. São Paulo: Saraiva, 2011.

BECKER, Alfredo Augusto. Teoria Geral do Direito Tributário. 6 ed. São Paulo: Noeses, 2013.

BRASIL. Ministério do Desenvolvimento Social. O que é e para que serve. 2015. Disponível em: <http://mds.gov.br/assuntos/cadastro-unico>. Acesso em: jul. 2018.

CALIENDO. Paulo. Da Justiça Fiscal: Conceito e Aplicação. Interesse Público. Porto Alegre, ano 6, no 29, p. 159-196, jan./fev. 2005.

CANADA. Government of Canada. Goods and services tax/Harmonized sales tax (GST/HST) credit. Canada, 2018. Disponível em: <https://www.canada.ca/en/revenueagency/services/child-family-benefits/goods-services-tax-harmonized-sales-tax-gst-hstcredit.html >. Acesso em: jun. 2018.

CARRAZZA, Roque Antonio. Curso de direito constitucional tributário. 29 ed. São Paulo: Malheiros Editores, 2013.

CARVAlHO, Paulo de Barros. Curso de Direito Tributário. 28 ed. São Paulo: Saraiva, 2017.

CAUREO, Elisângela Simon. Capacidade contributiva, tributação indireta e mínimo existencial. Revista da Procuradoria-Geral do Estado, Porto Alegre, v. 36 n. 76, p. 103$152,2015$.

COÊLHO, Sacha Calmon Navarro. Curso de Direito Tributário Brasileiro. 14 ed. Rio de Janeiro: Forense, 2015.

CONTI, José Maurício. Princípios Tributários da Capacidade Contributiva e da Progressividade. São Paulo: Dialética, 1996.

DANILEVICZ, Rosane Beatriz J. O princípio da essencialidade na tributação. Revista da FESDT. Porto Alegre, n. 3, p. 229-245, jan./jun. 2009.

DERZI, Misabel de Abreu Machado. Guerra fiscal, Bolsa Família e Silêncio (Relações, efeitos e regressividade). Revista Jurídica da Presidência. Brasília, v. 16, n. 108, p. 39-64, fev./maio 2014.

DIFINI, Luiz Felipe Silveira, Elementos para Fixação de Parâmetros para Concretização da Norma de Proibição de Tributos Confiscatórios. Revista do Instituto do Direito Brasileiro, Lisboa, n. 13, p. 14901-14930, 2013.

FALSITTA, Gaspare. Manuale di Diritto Tributario. Parte Generale. 5 ed. Padova: Cedam, 2005.

GIARDINA, Emilio. Le basi teoriche del princiio dela capacità contributiva. Milano: Dott. A. Giuffrè, 1961. 
GONÇALVES, Antônio Baptista. O controle fiscal ante a modernidade cibernética. Revista Tributária e de Finanças Públicas. São Paulo: vol. 101/2011, p. 313 - 324, nov.-dez. 2011.

HERRERA MOLINA, Pedro Manuel. Capacidad Económica y sistema fiscal: análisis del ordenamiento español a la luz del Derecho alemán. Madrid: Marcial Pons, 1998.

KIRCHHOF, Paul. Tributação no Estado Constitucional. Tradução de Pedro Adamy. São Paulo: Quartier Latin, 2016.

LAPATZA, Jose Juan Ferreiro. Sujetos Pasivos y Capacidad Económica. Revista de Direito Tributário. São Paulo, s/d. nº 59, p. 160-167, 2003.

LEHNER, Moris. Consideração Econômica e Tributação conforme a Capacidade Contributiva. Sobre a Possibilidade de uma Interpretação Teleológica de normas com Finalidades Arrecadatórias. Tradução de Luís Eduardo Schoueri. In: SCHOUERI, Luís Eduardo; ZILVETI, Fernando Aurelio (Coord.). Direito tributário: estudos em homenagem a Brandão Machado. São Paulo: Dialética, 1998, p. 143-154.

MACHADO, Hugo de Brito. Curso de Direito Tributário. 38. ed. São Paulo: Malheiros, 2017.

MOSCHETTI, Francesco. Il principio della capacità contributiva. Padova: Cedam, 1973.

OECD. Consumption Tax Trends 2016: VAT/GST and excise rates, trends and policy issues. Paris: OECD Publishing, 2016. Disponível em: 〈https://doi.org/10.1787/ctt-2016-en>. Acesso em: jun. 2018.

PASCHOAL, Bruno Vinicius Luchi. Punição, Recompensa, Persuasão e Ajuda: Estratégias regulatórias a partir do caso Nota Fiscal Paulista. São Paulo: 2012. Dissertação (Mestrado em Direito e Desenvolvimento). Fundação Getúlio Vargas. Escola de Direito de São Paulo. São Paulo: 2012.

POMERANZ, Jennifer L.; CHRIQUI, Jamie F. The Supplemental Nutrition Assistance Program: Analysis of Program Administration and Food Law Definitions. American Journal of Preventive Medicine. 49.3, p. 428-436, set. 2015. Disponível em: <https://www.ncbi.nlm.nih.gov/pmc/articles/PMC4922898/>. Acesso em: jun. 2018.

RIO GRANDE DO SUL. O que é o Programa NFG? 2018. Disponível em: https://nfg.sefaz.rs.gov.br/site/institucional_o_que_e.aspx>. Acesso em: jun. 2018.

SANTANA, Irailson Calado (Organ.). Estudos Tributários Carga Tributária no Brasil 2015: Análise por Tributo e Bases de Incidência. Brasília: Receita Federal, 2016.

SÃO PAUlO (Estado). Secretaria da Fazenda. Sobre a Nota Fiscal Paulista São Paulo: 2018. Disponível em: https://portal.fazenda.sp.gov.br/servicos/nfp. Acesso em: jun. 2018.

SILVA, Giovanni Padilha da. Personalização do IVA para o Brasil: harmonizando os objetivos de eficiência e equidade. Plataforma Política Social, 2018, p. 4-7. Disponível em: $<$ http://plataformapoliticasocial.com.br/wp-content/uploads/2018/02/TD_14.pdf $>$. Acesso em: jul. 2018. 
SILVEIRA, Fernando Gaiger. Tributação, Previdência e Assistência Sociais: impactos distributivos. Capinas: 2008. Tese (Doutorado em Economia Aplicada). Universidade Estadual de Campinas, Campinas, 2008.

TIPKE, Klaus; LANG, Joachim. Direito Tributário. Vol I. Tradução de Luiz Doria Furquim. Porto Alegre: Sergio Antonio Fabris Editor, 2008.

TIPKE, Klaus; YAMASHITA, Douglas. Justiça Fiscal e Princípio da Capacidade Contributiva. São Paulo: Malheiros Editores, 2002

UNITED STATES. United States Department of Agriculture. Food and Nutricion Service. Estados Unidos: 2018. Disponível em: <https://www.fns.usda.gov/snap/eligibility>. Acesso em jun. 2018.

VELLOSO, Andrei Pitten. Constituição tributária interpretada. 3 ed. Porto Alegre: Livraria do Advogado Editora, 2016.

Justiça Tributária. In: ÁVILA, Humberto (Org.). Fundamentos do Direito Tributário. São Paulo: Marcial Pons, 2012, p. 35-86.

VIANNA, Salvador Werneck; MAGALHÃES, Luís Carlos G.; SILVEIRA, Fernando Gaiger;

TOMICH, Frederico Andrade. Carga Tributária Direta e Indireta sobre as Unidades Familiares no Brasil: Avaliação de sua Incidência nas Grandes Regiões Urbanas em 1996. Brasília: IPEA, 2000.

WASHINGTON STATE. Department of Revenue. Food benefits under the Supplemental Nutrition Assistance Program (SNAP) or a successor program. Washington, 2018. Disponível em: <https://dor.wa.gov/get-form-or-publication/publications-subject/tax-topics>. Acesso em: jun. 2018.

ZILVETI, Fernando Aurelio. Capacidade Contributiva e Mínimo Existencial. In: SCHOUERI, Luís Eduardo; ZILVETI, Fernando Aurelio (Coord.). Direito tributário: estudos em homenagem a Brandão Machado. São Paulo: Dialética, 1998, p. 36-47.

ZOCKUN, Maria Helena (coord.). Simplificando o Brasil: propostas de reforma na relação econômica do governo com o setor privado. Texto para Discussão n. 3, São Paulo: Fundação Instituto de Pesquisas Econômicas, 2007. 